\title{
Gallic acid inhibits the growth of calf pulmonary arterial endothelial cells through cell death and glutathione depletion
}

\author{
WOO HYUN PARK
}

\begin{abstract}
Department of Physiology, Medical School, Research Institute for Endocrine Sciences, Chonbuk National University, Jeonju, Jeollabuk 54907, Republic of Korea
\end{abstract}

Received August 25, 2016; Accepted March 3, 3017

DOI: $10.3892 / \mathrm{mmr} .2017 .7585$

\begin{abstract}
Gallic acid (GA) exhibits a number of cellular effects, including apoptosis, which is associated with oxidative stress. The present study investigated the effects of GA on calf pulmonary arterial endothelial cell (CPAEC) growth and death, along with the levels of reactive oxygen species (ROS) and glutathione (GSH). GA treatment inhibited the growth of CPAECs at $24 \mathrm{~h}$, and the half-maximal inhibitory concentration $\left(\mathrm{IC}_{50}\right)$ value of $\mathrm{GA}$ was $\sim 30 \mu \mathrm{M}$. GA treatment also induced cell death, which was accompanied by a loss of mitochondrial membrane potential $\left(\Delta \Psi_{\mathrm{m}}\right)$. GA treatment in CPAECs resulted in decreased ROS levels, including $\mathrm{O}_{2}{ }^{-}$, whereas the number of GSH-depleted cells increased. Neither a pan-caspase inhibitor (benzyloxycarbonyl-Val-Ala-Asp-fluoromethylketone) nor buthionine sulfoximine treatment affected GA-induced cell growth inhibition, cell death, ROS and GSH levels in CPAECs, whereas co-treatment with $\mathrm{N}$-acetyl-cysteine (NAC) resulted in enhanced cell growth inhibition, cell death and $\Delta \Psi_{\mathrm{m}}$ loss in these cells. Although NAC treatment did not significantly influence ROS levels in GA-treated CPAECs, it significantly enhanced GSH depletion in these cells. In conclusion, GA inhibited the growth of CPAECs via cell death, which was associated with GSH depletion rather than alterations to ROS levels.
\end{abstract}

Correspondence to: Professor Woo Hyun Park, Department of Physiology, Medical School, Research Institute for Endocrine Sciences, Chonbuk National University, 20 Geonji-ro, Deokjin, Jeonju, Jeollabuk 54907, Republic of Korea

E-mail: parkwh71@jbnu.ac.kr

Abbreviations: $\Delta \Psi_{\mathrm{m}}$, mitochondrial membrane potential; BSO, 1-buthionine sulfoximine; CMFDA, 5-chloromethylfluorescein diacetate; CPAEC, calf pulmonary arterial endothelial cell; DHE, dihydroethidium; EC, endothelial cell; FITC, fluorescein isothiocyanate; GA, gallic acid; GSH, glutathione; H2DCFDA, 2',7'-dichlorodihydrofluorescein diacetate; MTT, 3-(4,5-dimethylthiazol-2-yl)-2,5-diphenyltetrazolium bromide; NAC, $\mathrm{N}$-acetyl cysteine; PI, propidium iodine; ROS, reactive oxygen species; Z-VAD-FMK, benzyloxycarbonyl-Val-Ala-Asp-fluoromethylketone.

Key words: gallic acid, cell death, calf pulmonary arterial endothelial cells, reactive oxygen species, glutathione

\section{Introduction}

Gallic acid (GA) is found in a variety of fruits and foods, and is well absorbed in human body (1). GA has been reported to have diverse biological and pharmacological behaviors, such as antibacterial and antiviral effects $(2,3)$. However, the most notable role of GA is associated with its anticancer activity, which has been reported in lung cancer $(4,5)$, leukemia (6) and prostate cancer (7), as well as breast, gastric, colon, cervical and esophageal cancers $(8,9)$. GA-induced apoptosis has been associated with oxidative stress derived from reactive oxygen species (ROS) (4-6,10). The central components of ROS are hydrogen peroxide $\left(\mathrm{H}_{2} \mathrm{O}_{2}\right)$, hydroxyl radical $(\mathrm{OH})$ and superoxide anion $\left(\mathrm{O}_{2}^{*}\right)$, which are generated as by-products of mitochondrial respiration or certain oxidases (11). $\mathrm{O}_{2}{ }^{-}$is metabolized to $\mathrm{H}_{2} \mathrm{O}_{2}$ by superoxide dismutases, and $\mathrm{H}_{2} \mathrm{O}_{2}$ is further detoxified to $\mathrm{O}_{2}$ and $\mathrm{H}_{2} \mathrm{O}$ by catalase or glutathione (GSH) peroxidases (11). Oxidative stress occurs due to the overproduction of ROS and/or the decreased decomposition of them. GA-induced cell death has also been correlated with mitochondrial dysfunction and increased intracellular $\mathrm{Ca}^{2+}$ level $(4,5,12)$; however, GA treatment did not lead to cytotoxicity in normal rat fibroblast and endothelial cells (13). In addition, GA exhibited potential antiapoptotic effects in normal human lymphocytes (14) and protected rat insulinoma RINm5F $\beta$-cells from glucolipotoxicity through its antiapoptotic mechanism (15). Controversially, GA was suggested to have pro-oxidative in addition to antioxidative properties, depending on the levels of iron or $\mathrm{H}_{2} \mathrm{O}_{2}(16,17)$. Therefore, additional studies are required to reassess the cellular properties of GA under diverse conditions.

Vascular endothelial cells (ECs) are involved in the regulation of inflammation, blood pressure and angiogenesis (18). Vascular ECs experience a broad range of oxidative stress, which may ultimately lead to endothelial dysfunction through the induction of apoptosis (19). Angiogenesis is a crucial step in the transition of a dormant tumor into a malignant state; the proliferation of ECs is an early step during sprouting angiogenesis. Despite important roles of vascular ECs in tumor biogenesis and development, the effects of GA on ECs are relatively poorly understood. In the vasculature, ROS serve physiological and pathophysiological roles through the regulation of numerous cellular processes, including cell proliferation, death and survival (19). Therefore, further research is required to explore the cellular effects of GA on ECs in relation to the 
levels of ROS and GSH expression. Calf pulmonary arterial ECs (CPAECs) are an established cell model for both cellular and molecular endothelial cell research $(20,21)$.

The present study investigated the effects of GA exposure on CPAEC growth and death in relation to ROS and GSH levels, and examined whether the antioxidant $\mathrm{N}$-acetyl cysteine (NAC) and the GSH synthesis inhibitor L-buthionine sulfoximine (BSO) were able to affect GA-induced CPAEC death.

\section{Materials and methods}

Cell culture. CPAECs were obtained from Korean Cell Line Bank (Seoul, Korea) and were cultured in RPMI-1640 medium (GE Healthcare Life Sciences, Little Chalfont, UK) supplemented with $10 \%$ fetal bovine serum (FBS; Sigma-Aldrich; Merck KGaA, Darmstadt, Germany) and 1\% penicillin-streptomycin (Gibco; Thermo Fisher Scientific, Inc., Waltham, MA, USA). CPAECs were routinely grown in $100 \mathrm{~mm}$ plastic tissue culture dishes (Nalge Nunc International, Penfield, NY, USA) in humidified incubator containing $5 \% \mathrm{CO}_{2}$ at $37^{\circ} \mathrm{C}$ and harvested with a solution of trypsin-EDTA (Gibco; Thermo Fisher Scientific, Inc.) while in the logarithmic phase of growth.

Reagents. GA (Sigma-Aldrich; Merck KGaA) was dissolved in $100 \%$ ethanol to $200 \mathrm{mM}$, and used at the indicated concentrations. The pan-caspase inhibitor benzyloxycarbonyl-Val-Ala-Asp-fluoromethylketone (Z-VAD-FMK; R\&D Systems, Inc., Minneapolis, MN, USA) was dissolved in DMSO (Sigma-Aldrich; Merck KGaA) to $10 \mathrm{mM}$. NAC and BSO were obtained from Sigma-Aldrich (Merck KGaA). NAC $200 \mathrm{mM}$ as a stock solution was dissolved in the buffer of $20 \mathrm{mM}$ 4-(2-hydroxyethyl)-1-piperazineethanesulphonic acid [HEPES; (pH 7.0)], and BSO $100 \mathrm{mM}$ as a stock solution was dissolved in distilled water. Based on a previous study (22), cells were pre-incubated at $37^{\circ} \mathrm{C}$ for $1 \mathrm{~h}$ with Z-VAD-FMK $(15 \mu \mathrm{M})$, NAC $(2 \mathrm{mM})$ or BSO $(10 \mu \mathrm{M})$, followed by treatment with the GA $(25 \mu \mathrm{M})$ at $37^{\circ} \mathrm{C}$ for $24 \mathrm{~h}$ before the assays were performed.

Cell proliferation assay. Viable and dead cell numbers and cell proliferation were determined by trypan blue staining and MTT dye absorbance by living cells, respectively, as previously described $(23,24)$. Briefly, $2 \times 10^{5}$ cells/well in 24 -well plates (Nalge Nunc International) were seeded for cell counting and $5 \times 10^{3}$ cells/well in 96-well microtiter plates (Nalge Nunc International) were seeded for MTT assays. The cells which were cultured in RPMI-1640 medium (GE Healthcare Life Sciences) supplemented with $10 \%$ fetal bovine serum (FBS; Sigma-Aldrich; Merck KGaA) and $1 \%$ penicillin-streptomycin (Gibco; Thermo Fisher Scientific, Inc.) were exposed to the indicated amounts of GA (between 0 and $50 \mu \mathrm{M}$ ) at $37^{\circ} \mathrm{C}$ for $24 \mathrm{~h}$ and/or $1 \mathrm{~h}$ pre-incubation with Z-VAD-FMK $(15 \mu \mathrm{M})$, NAC $(2 \mathrm{mM})$ or BSO $(10 \mu \mathrm{M})$ at $37^{\circ} \mathrm{C}$. The plates were incubated for $4 \mathrm{~h}$ at $37^{\circ} \mathrm{C}$. Medium in plates was removed by pipetting, and $200 \mu \mathrm{l}$ DMSO was added to each well to solubilize the formazan crystals. The optical density was measured at $570 \mathrm{~nm}$ using a microplate reader $\left(\right.$ Synergy $^{\mathrm{TM}} 2$; BioTek Instruments Inc., Winooski, VT, USA).
Sub-G1 analysis. Cells at the sub-G1 phase were determined by staining with propidium iodide [PI; Sigma-Aldrich; Merck KGaA; excitation (Ex)/emission $(E m)=488 / 617 \mathrm{~nm}$ ], as previously described (25). Briefly, $1 \times 10^{6}$ cells cultured in RPMI-1640 medium (GE Healthcare Life Sciences) supplemented with 10\% FBS (Sigma-Aldrich; Merck KGaA) and $1 \%$ penicillin-streptomycin (Gibco; Thermo Fisher Scientific, Inc.) in 60-mm culture dish (Nalge Nunc International) were exposed to the indicated amounts of GA and/or Z-VAD-FMK, NAC or BSO at $37^{\circ} \mathrm{C}$ for $24 \mathrm{~h}$. Cells were then washed in PBS and fixed in $70 \%$ ethanol at $4^{\circ} \mathrm{C}$ for $1 \mathrm{~h}$. Cells were again washed with PBS and then incubated with PI $(10 \mu \mathrm{g})$ with simultaneous treatment with RNase at $37^{\circ} \mathrm{C}$ for $30 \mathrm{~min}$. Cellular DNA content was measured with a FACStar Flow Cytometer (BD Biosciences, Franklin Lakes, NJ, USA) and analyzed using lysis II and Cellfit software (version 2.0; BD Biosciences).

Annexin V-fluorescein isothiocyanate (FITC)/PI staining for cell death detection. Cell death was measured by staining cells with Annexin V-FITC (Ex/Em=488/519 nm; Molecular Probes; Thermo Fisher Scientific, Inc.) and PI $(\mathrm{Ex} / \mathrm{Em}=488 / 617 \mathrm{~nm}$; Sigma-Aldrich; Merck KGaA), as previously described (26). Briefly, $1 \times 10^{6}$ cells in $60 \mathrm{~mm}$ culture dish (Nalge Nunc International) were incubated with the indicated amounts of GA with or without Z-VAD-FMK, NAC or BSO at $37^{\circ} \mathrm{C}$ for $24 \mathrm{~h}$. The prepared cells were washed twice with cold PBS and then resuspended in $500 \mu 1$ of binding buffer [ $10 \mathrm{mM}$ HEPES/NaOH (pH 7.4), $140 \mathrm{mM} \mathrm{NaCl}, 2.5 \mathrm{mM} \mathrm{CaCl}_{2}$ ] at a concentration of $1 \times 10^{6}$ cells $/ \mathrm{ml}$. Then $5 \mu \mathrm{l}$ of annexin V-FITC (BD Biosciences) and $10 \mu \mathrm{l}$ of $20 \mu \mathrm{g} / \mathrm{ml}$ PI were added to these cells. Annexin V-FITC/PI staining was analyzed with a FACStar flow cytometer (BD Biosciences) and CellQuest Pro software (version 5.1; BD Biosciences).

Measurement of mitochondrial membrane potential $\left(\Delta \Psi_{m}\right)$. $\Delta \Psi_{\mathrm{m}}$ was measured using the Rhodamine 123 mitochondrial-specific fluorescent dye (Sigma-Aldrich; Merck KGaA; $\mathrm{Ex} / \mathrm{Em}=485 / 535 \mathrm{~nm}$ ), as previously described (23). Briefly, $1 \times 10^{6}$ cells in $60 \mathrm{~mm}$ culture dish (Nalge Nunc International) were incubated with the indicated amounts of GA with or without Z-VAD-FMK, NAC or BSO at $37^{\circ} \mathrm{C}$ for $24 \mathrm{~h}$. Cells were washed twice with PBS and incubated with Rhodamine $123(0.1 \mu \mathrm{g} / \mathrm{ml})$ at $37^{\circ} \mathrm{C}$ for $30 \mathrm{~min}$. Rhodamine 123 staining intensity was determined by FACStar flow cytometry (BD Biosciences) and analyzed using CellQuest Pro software (version 5.1; BD Biosciences). An absence of Rhodamine 123 from cells indicated the loss of $\Delta \Psi_{\mathrm{m}}$ in CPAECs.

Detection of intracellular ROS levels. Intracellular ROS levels were assessed with the non-fluorescent probe dye 2',7'-dichlorodihydrofluorescein diacetate $\left(\mathrm{H}_{2} \mathrm{DCFDA}\right.$; Ex/Em=495/529 nm; Molecular Probes; Thermo Fisher Scientific, Inc.); cleavage of the acetate groups converts H2DCFDA into the highly fluorescent 2',7'-dichloroflurosceine (DCF). Dihydroethidium (DHE; Ex/Em=518/605 nm; Molecular Probes; Thermo Fisher Scientific, Inc.) is a fluorogenic probe that is highly selective for $\mathrm{O}_{2}^{-}$. Briefly, $1 \times 10^{6}$ cells in $60 \mathrm{~mm}$ culture dish (Nalge Nunc International) were incubated with the indicated amounts of GA with or without Z-VAD-FMK, NAC or BSO at $37^{\circ} \mathrm{C}$ 

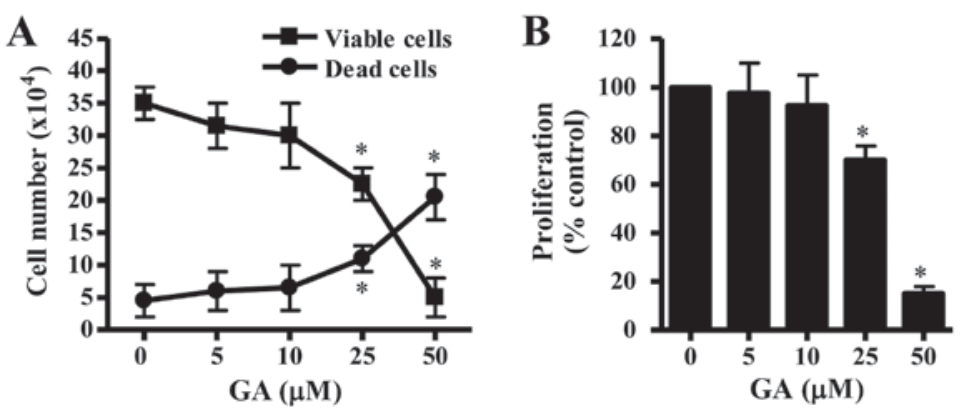

Figure 1. Effects of GA on CPAEC proliferation. Exponentially growing CPAECs were treated with the indicated concentrations of GA for 24 h. (A) Total viable vs. dead cell numbers were assessed by trypan blue cell counting. (B) Cell proliferation was assessed by MTT assay. ${ }^{*} \mathrm{P}<0.05$ compared with untreated (0 $\mu \mathrm{M}$ GA) control group. CPAEC, calf pulmonary arterial endothelial cell; GA, gallic acid; MTT, 3-(4,5-dimethylthiazol-2-yl)-2,5-diphenyltetrazolium bromide.

for $24 \mathrm{~h}$. Following incubation, cells were washed with PBS and incubated with $\mathrm{H}_{2}$ DCFDA $(20 \mu \mathrm{M})$ or DHE $(20 \mu \mathrm{M})$ at $37^{\circ} \mathrm{C}$ for $30 \mathrm{~min}$. DCF and DHE fluorescence was detected with a FACStar flow cytometer (BD Biosciences). ROS and $\mathrm{O}_{2}^{--}$levels were expressed as the mean fluorescence intensity, which was calculated by CellQuest Pro software (version 5.1; BD Biosciences).

Detection of the intracellular glutathione (GSH). Cellular GSH expression levels were analyzed using 5-chloromethylfluorescein diacetate (CMFDA; Ex/Em=522/595 nm; Molecular Probes; Thermo Fisher Scientific, Inc.), as previously described (27). Briefly, $1 \times 10^{6}$ cells in $60 \mathrm{~mm}$ culture dish (Nalge Nunc International) were incubated with the indicated amounts of GA with or without Z-VAD-FMK, $\mathrm{NAC}$ or BSO at $37^{\circ} \mathrm{C}$ for $24 \mathrm{~h}$. The cells were then washed in PBS. They were then incubated with $5 \mu \mathrm{M}$ CMFDA at $37^{\circ} \mathrm{C}$ for $30 \mathrm{~min}$. Fluorescence intensity of the cleaved CMF was determined using a FACStar flow cytometer (BD Biosciences) and analyzed using CellQuest Pro software (version 5.1; BD Biosciences).

Statistical analysis. The results represent the mean of at least three independent experiments \pm standard deviation. Student's t-test or one-way analysis of variance with post hoc analysis using Tukey's multiple comparison test for parametric data. $\mathrm{P}<0.05$ was considered to indicate a statistically significant difference.

\section{Results}

Effects of GA on cell growth, cell death and $\triangle \Psi_{m}$ in CPAECs. The effects of GA exposure on the growth of CPAECs were examined by counting the number of trypan blue positive- and negative-stained cells. Cells treated with various concentrations of GA for $24 \mathrm{~h}$ exhibited a dose-dependent decrease in the population of viable (trypan blue negative) CPAEC cells (Fig. 1A), whereas the number of dead (trypan blue positive) cells increased. The ratio of dead cells to viable cells rose in a dose-dependent manner. Changes in cell proliferation were assessed by MTT assay. CPAEC cells that were treated with GA for $24 \mathrm{~h}$ exhibited a reduction in proliferation, and the half-maximal inhibitory concentration $\left(\mathrm{IC}_{50}\right)$ value of $\mathrm{GA}$ in CPAEC cells was $\sim 30 \mu \mathrm{M}$ at $24 \mathrm{~h}$ (Fig. 1B).
In addition, GA treatment enhanced the number of sub-G1 cells, which indicates cell death, in a dose-dependent manner (Fig. 2A). At a dose of $25 \mu \mathrm{M}$ GA, the number of sub-G1 cells increased $\sim 13 \%$ compared with the untreated control CPAECs (Fig. 2A). Whether GA was able to induce apoptosis in CPAECs was examined further. As shown in Fig. 2B, the number of Annexin V-FITC-stained cells increased in CPAECs as the concentration of GA increased. At a dose of $25 \mu \mathrm{M}$ GA, the number of Annexin V-FITC-stained cells increased by $\sim 16 \%$ compared with the untreated control CPAECs (Fig. 2B). Since apoptosis is closely related to a collapse of $\Delta \Psi_{\mathrm{m}}$, the effects of GA on $\Delta \Psi_{\mathrm{m}}$ were assessed using rhodamine 123 dye. Treatment with GA triggered the loss of $\Delta \Psi_{\mathrm{m}}$ [that is, (-) rhodamine 123 cells] in CPAECs in a dose-dependent manner (Fig. 2C). CPAEC cells treated with $25 \mu \mathrm{M}$ GA exhibited $\sim 10 \%$ decrease in $\Delta \Psi_{\mathrm{m}}$ compared with untreated control cells, whereas $50 \mu \mathrm{M}$ GA treatment strongly increased the loss by $\sim 70 \%$ (Fig. 2C).

Effects of GA on intracellular ROS and GSH levels in CPAECs. To assess the levels of intracellular ROS in GA-treated CPAECs at $24 \mathrm{~h}, \mathrm{H}_{2}$ DCFDA and DHE fluorescent dyes were used. ROS levels, as measured by mean DCF fluorescence intensity, were not significantly altered in CPAECs treated with 5,10 or $25 \mu \mathrm{M}$ GA, whereas the ROS level was significantly decreased by $50 \mu \mathrm{M}$ GA treatment, compared with untreated control cells (Fig. 2D). The level of red fluorescence derived from DHE, which indicates the level of $\mathrm{O}_{2}{ }^{--}$in the cell, decreased significantly in CPAECs treated with 5,10 or $25 \mu \mathrm{M}$ GA (Fig. 2E); however, the level was not significantly altered when cells were treated with $50 \mu \mathrm{M}$ GA.

Finally, changes in the levels of GSH expression in CPAECs were analyzed using a CMFDA fluorescence dye. GA treatment led to a dose-dependent increase in the number of GSH-depleted cells [(-) CMF; Fig. 2F]. CPAECs treated with $25 \mu \mathrm{M}$ GA exhibited $\sim 11 \%$ increase in the number of GSH-depleted cells compared with untreated control cells.

Effects of Z-VAD-FMK, NAC and BSO on cell growth, cell death and $\triangle \Psi_{m}$ in GA-treated CPAECs. In these experiments, $25 \mu \mathrm{M}$ GA was used as a suitable dose to differentiate the levels of proliferation and apoptosis in the presence or absence of Z-VAD-FMK $(15 \mu \mathrm{M})$, NAC (2 mM) or BSO $(10 \mu \mathrm{M})$ since the $\mathrm{IC}_{50}$ value of GA in CPAEC cells was $\sim 30 \mu \mathrm{M}$. Treatment with Z-VAD-FMK, NAC or BSO alone 

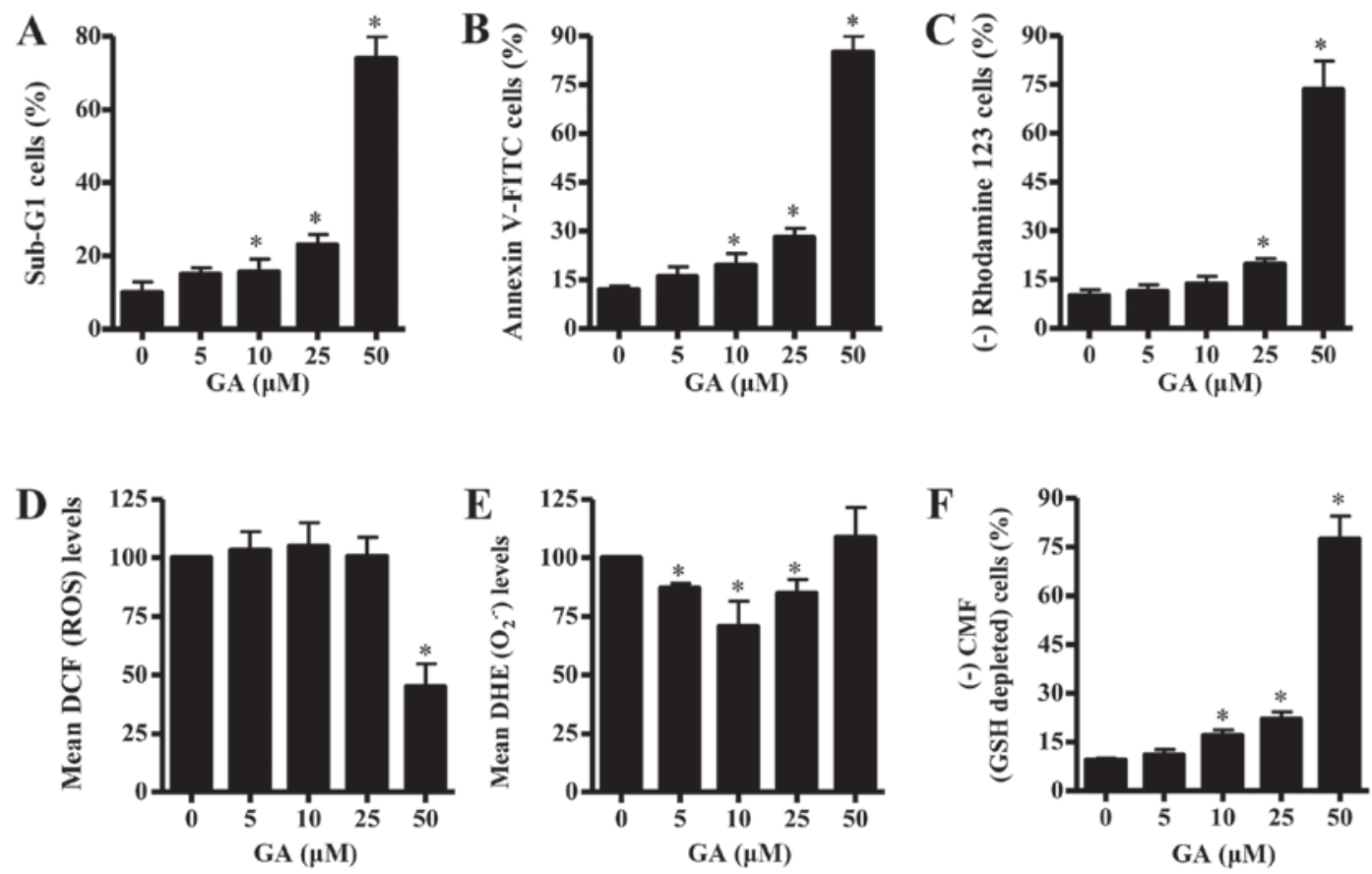

Figure 2. Effects of GA on cell death, $\Delta \Psi_{\mathrm{m}}$, ROS and GSH levels in CPAECs. Exponentially growing CPAEC cells were treated with the indicated concentrations of GA for $24 \mathrm{~h}$, and various aspects were examined by FACStar flow cytometry, including: (A) The percentage of cells at sub-G1 phase; (B) the percentage of cells staining positive for Annexin V-FITC; (C) the percentage of cells with reduced $\Delta \Psi_{\mathrm{m}}$, as measured by (-) rhodamine 123 staining; (D) the mean ROS levels, as measured by DCF fluorescence intensity; (E) the mean $\mathrm{O}_{2}{ }^{-}$levels, as measured by DHE fluorescence intensity; and (F) the percentage of GSH-depleted cells, as measured by (-) CMF fluorescence. " $\mathrm{P}<0.05$ compared with untreated ( $0 \mu \mathrm{M} \mathrm{GA})$ control group. $\Delta \Psi_{\mathrm{m}}$, mitochondrial membrane potential; CMF, 5-chloromethylfluorescein; CPAEC, calf pulmonary arterial endothelial cell; DCF, 2',7'-dichlorofluorescein; DHE, dihydroethidium; FITC, fluorescein isothiocyanate; GA, gallic acid; GSH, glutathione; $\mathrm{O}_{2}^{-}{ }^{-}$, superoxide anion; ROS, reactive oxygen species.

did not significantly affect the growth of CPAECs at $24 \mathrm{~h}$ (Fig. 3A). GA-treated CPAEC cells were unaffected by co-treatment with either Z-VAD-FMK or BSO, whereas the GA-induced growth inhibition was strongly enhance by NAC exposure (Fig. 3A).

In relation to cell death and $\Delta \Psi_{\mathrm{m}}$, the number of sub-G1 cells in GA-treated CPAECs that were also treated with Z-VAD-FMK and BSO did not significantly change, whereas co-treatment with NAC resulted in an increase in the number of CPAEC cells at sub-G1 (Fig. 3B). Similarly, neither Z-VAD-FMK nor BSO treatment affected the number of Annexin V-FITC-stained cells in GA-treated CPAECs, whereas GA and NAC co-treatment significantly increased the number in these apoptotic cells (Fig. 3C and D). Treatment with $25 \mu \mathrm{M}$ GA did not significantly trigger necrotic cell death (that is, cells staining positive for PI and negative for Annexin V-FITC) in CPAECs (Fig. 3C and E). However, NAC co-treatment strongly induced necrotic cell death in CPAECs treated with $25 \mu \mathrm{M} \mathrm{GA}$, whereas treatment with Z-VAD-FMK or BSO did not (Fig. 3C and E). Similarly, neither Z-VAD-FMK nor BSO co-treatment was able to affect the level of $\Delta \Psi_{\mathrm{m}}$ loss [as measured by (-) rhodamine 123 expression] in GA-treated CPAECs, but co-treatment with NAC significantly augmented the loss of $\Delta \Psi_{\mathrm{m}}$ in these cells (Fig. 4A and B).

Effects of Z-VAD-FMK, NAC or BSO on ROS, $\mathrm{O}_{2}{ }^{-}$and GSH levels in GA-treated CPAECs. ROS and GSH levels in GA-treated CPAECs were examined to assess any changes in their expression levels due to treatment with Z-VAD-FMK,
NAC or BSO at $24 \mathrm{~h}$. Neither Z-VAD-FMK nor NAC treatment resulted in a change in ROS levels (as determined by DCF fluorescence intensity) in GA-treated CPAECs (Fig. 5A); although co-treatment with BSO appeared to slightly increase the ROS level, this increase was not significant. Cells treated with NAC alone appeared to exhibit a mild reduction in the basal level of ROS, but this was not significant (Fig. 5A). In relation to $\mathrm{O}_{2}{ }^{-1}$ levels (as measured by mean DHE fluorescence intensity), none of the co-treatments with Z-VAD-FMK, NAC or BSO significantly affected the GA-induced reduction in $\mathrm{O}_{2}{ }^{-}$levels in CPAEC cells (Fig. 5B). Cells treated BSO alone exhibited a significant increase in $\mathrm{O}_{2}{ }^{-}$level compared with untreated control CPAECs (Fig. 5B). Although co-treatment with Z-VAD-FMK or BSO did not significantly affect the levels of GSH depletion (as measured by absence of CMF fluorescence) in GA-treated CPAECs, cells co-treated with NAC significantly increased the number of GSH-depleted cells (Fig. 5C and D). Notably, cells treated with BSO alone exhibited an increased number of GSH-depleted cells compared with untreated control CPAECs (Fig. 5C and D).

\section{Discussion}

A number of previous studies have reported that GA exposure inhibited the growth of HeLa cervical cancer cells and Calu-6 and $\mathrm{A} 549$ lung cancer cells, and the $\mathrm{IC}_{50}$ was between 30 and $150 \mu \mathrm{M}$ in these cell lines $(4,5,9)$. In the present study, GA treatment decreased the growth of CPAECs in a dose-dependent manner, with the $\mathrm{IC}_{50}$ value of $\sim 30 \mu \mathrm{M}$ at $24 \mathrm{~h}$. Conversely, 
A

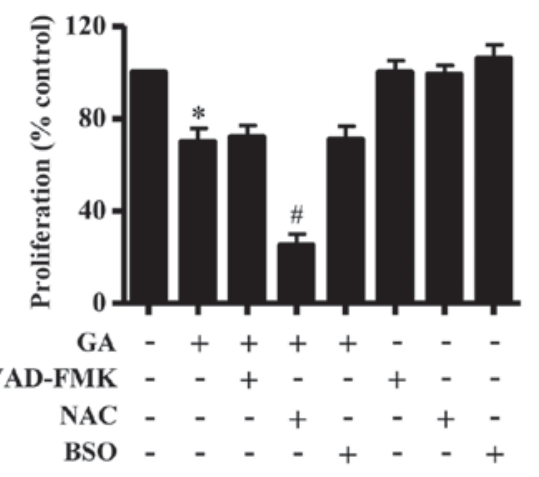

C
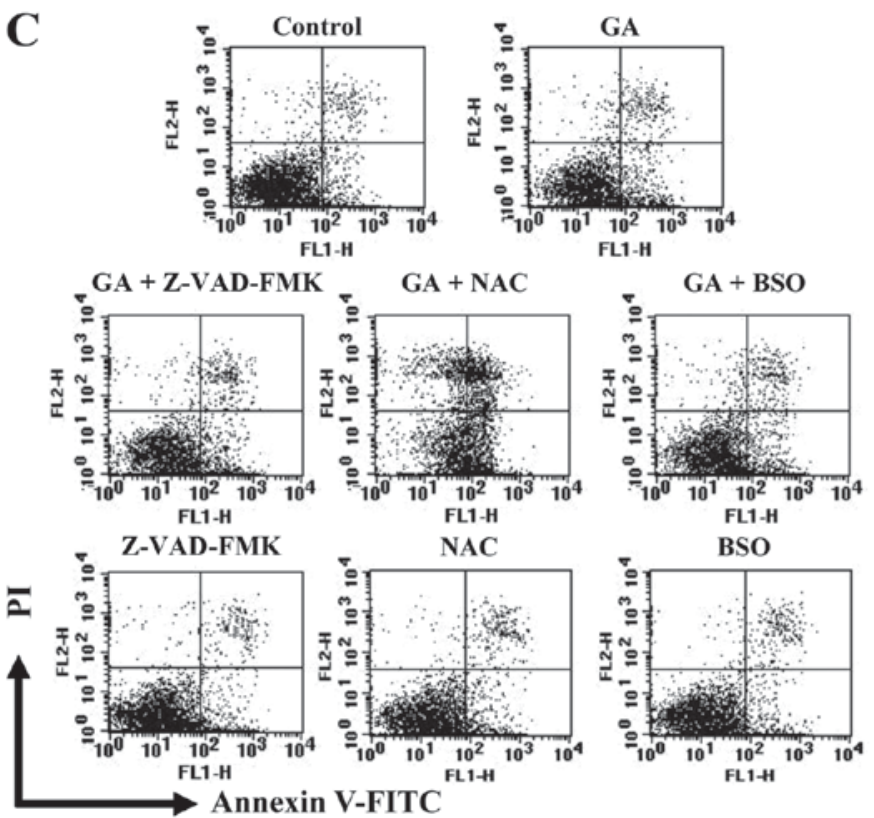

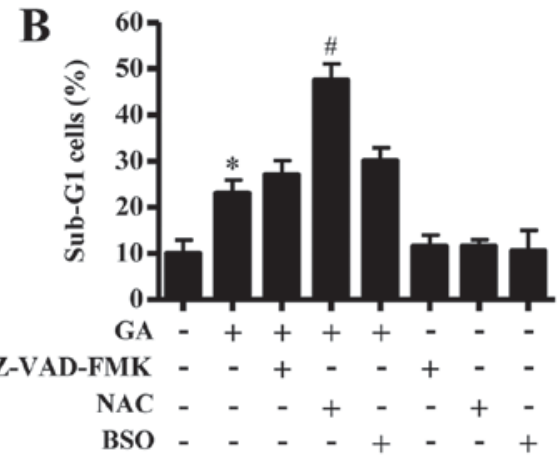

D
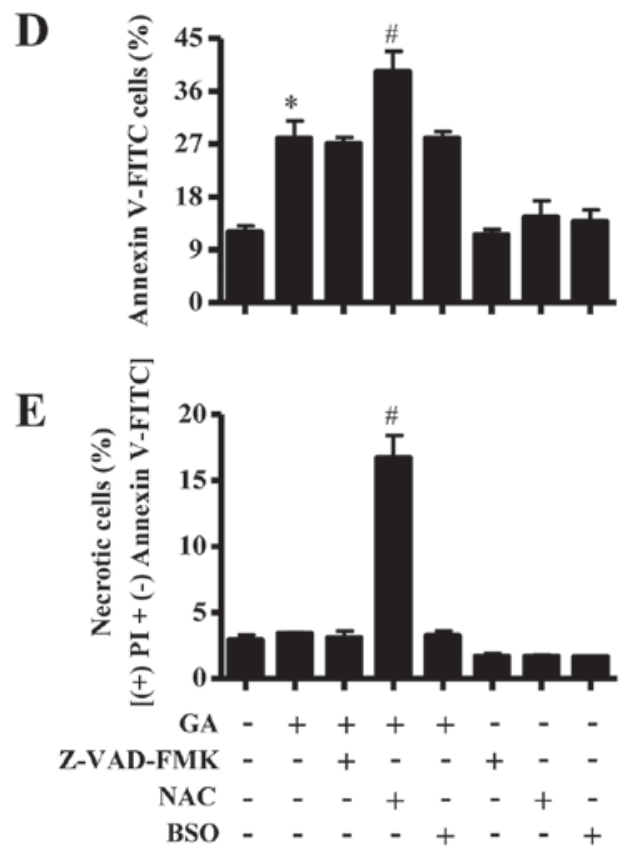

Figure 3. Effects of Z-VAD-FMK, NAC or BSO on cell growth and death in GA-treated CPAECs. Exponentially growing cells were pretreated with Z-VAD-FMK $(15 \mu \mathrm{M})$, NAC $(2 \mathrm{mM})$ or BSO $(10 \mu \mathrm{M})$, followed by GA $(25 \mu \mathrm{M})$ for $24 \mathrm{~h}$. (A) Changes to cell proliferation were assessed by MTT assay. (B) The percentage of cells at sub-G1 phase. (C) Representative FACStar flow cytometry plots for Annexin V-FITC/PI staining in CPAEC cells. (D) Percentage of Annexin V-FITC-positive staining cells from (C). (E) Percentage of necrotic cells from (C), necrotic cells are PI-positive and Annexin V-FITC-negative. ${ }^{*} \mathrm{P}<0.05$ compared with untreated control group; ${ }^{\text {P }}<0.05$ compared with GA-treated control group. BSO, L-buthionine sulfoximine; CPAEC, calf pulmonary arterial endothelial cell; FITC, fluorescein isothiocyanate; GA, gallic acid; MTT, 3-(4,5-dimethylthiazol-2-yl)-2,5-diphenyltetrazolium bromide; NAC, $\mathrm{N}$-acetyl cysteine; PI, propidium iodine; Z-VAD-FMK, benzyloxycarbonyl-Val-Ala-Asp-fluoromethylketone.

GA treatment was previously demonstrated to have no relative cytotoxicity in normal fibroblasts and ECs $(13,28,29)$. CPAECs appeared less resistant to GA treatment compared with other normal cells, and instead they were similar to cancer cells in their susceptibility to GA exposure. These differences may be due to the differing activities and antioxidant systems in each cell line.

GA treatment has previously been demonstrated to induce apoptosis in cancer cells through mitochondrial dysfunction $(4,5,10)$. In the present study, GA exposure appeared to induce apoptosis in CPAECs, as evidenced by the increase in the number of sub-G1 cells and Annexin V-FITC-positive staining cells, and it triggered the loss of $\Delta \Psi_{\mathrm{m}}$. The dose-dependent loss of $\Delta \Psi_{\mathrm{m}}$ corresponded to the dose-dependent rise in Annexin V-FITC staining cells, supporting the hypothesis that GA-induced cell death may be tightly correlated with the collapse of $\Delta \Psi_{\mathrm{m}}$. In particular, the tested dose of $15 \mu \mathrm{M}$ Z-VAD-FMK used in the present study did not affect cell death or $\Delta \Psi_{\mathrm{m}}$ in GA-treated CPAECs. However, $15 \mu \mathrm{M}$ Z-VAD-FMK was reported to significantly reduce cell death and $\Delta \Psi_{\mathrm{m}}$ loss in CPAECs treated with pyrogallol, a derivative of GA (20). Therefore, this result suggested that the activation of caspases is not closely related to GA-induced apoptosis in CPAECs. It has also been reported that Z-VAD-FMK effectively prevented GA-induced apoptosis in lung cancer cells (30). Therefore, the modes of caspase activation during GA-induced apoptosis may be dependent on cell types (e.g., normal cells vs. cancer cells) and the difference requires further study.

GA exhibits both pro- and antioxidative properties $(16,17)$. Results from a number of previous studies suggested that GA-induced apoptosis may be associated with oxidative stress derived from ROS $(4-6,10)$. However, treatment with the lower doses of GA (5-25 $\mu \mathrm{M})$ did not increase ROS levels in CPAECs in the present study, whereas a dose of $50 \mu \mathrm{M}$ GA induced CPAEC death and decreased ROS levels. Conversely, 
A
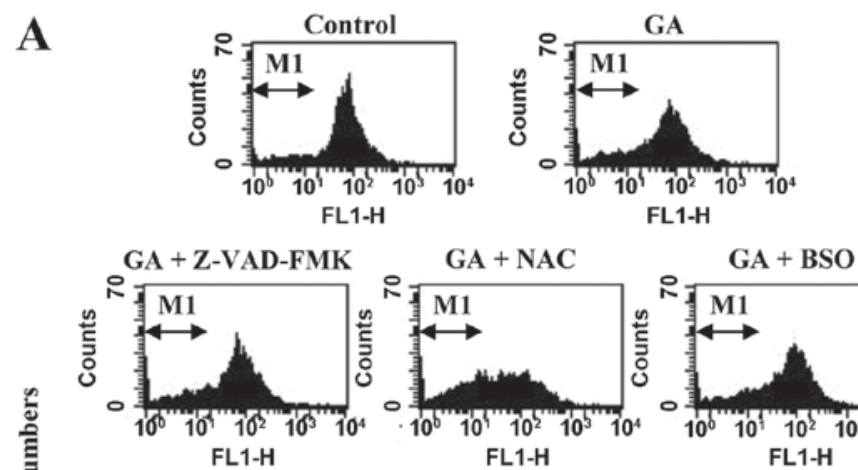

อ
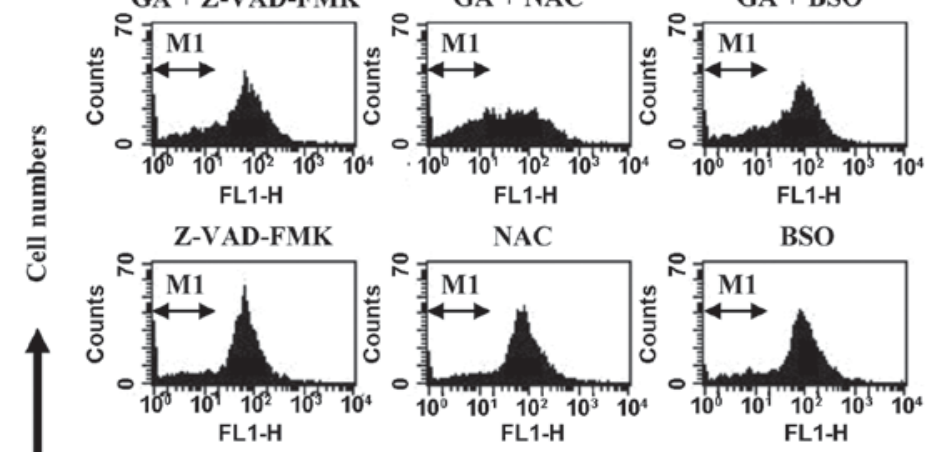

BSO

Rhodamine 123
B

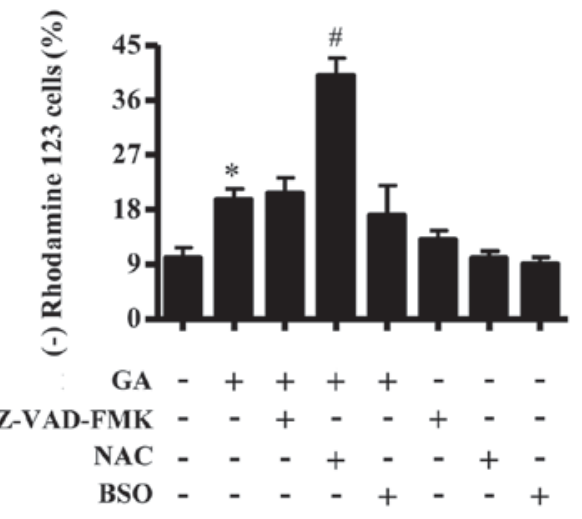

Figure 4. Effects of Z-VAD-FMK, NAC or BSO on $\Delta \Psi_{\mathrm{m}}$ in GA-treated CPAECs. Exponentially growing cells were pretreated with Z-VAD-FMK (15 $\mu \mathrm{M}$ ), NAC $(2 \mathrm{mM})$ or BSO $(10 \mu \mathrm{M})$, followed by GA $(25 \mu \mathrm{M})$ for $24 \mathrm{~h} . \Delta \Psi_{\mathrm{m}}$ was determined in CPAECs by measuring rhodamine 123 fluorescence levels with a FACStar flow cytometer. (A) Representative FACStar flow cytometry plots for (+) rhodamine 123 staining in CPAECs. M1 indicates $\Delta \Psi_{\mathrm{m}}$ loss. (B) Percentage of rhodamine 123-negative $\left(\Delta \Psi_{\mathrm{m}}\right.$ loss) cells from the M1 region in $\mathrm{A}$. " $\mathrm{P}<0.05$ compared with untreated $\left(0 \mu \mathrm{M}\right.$ GA) control group; ${ }^{*} \mathrm{P}<0.05$ compared with GA-treated control group. $\Delta \Psi_{\mathrm{m}}$, mitochondrial membrane potential; BSO, L-buthionine sulfoximine; CPAEC, calf pulmonary arterial endothelial cell; GA, gallic acid; NAC, N-acetyl cysteine; Z-VAD-FMK, benzyloxycarbonyl-Val-Ala-Asp-fluoromethylketone.

A

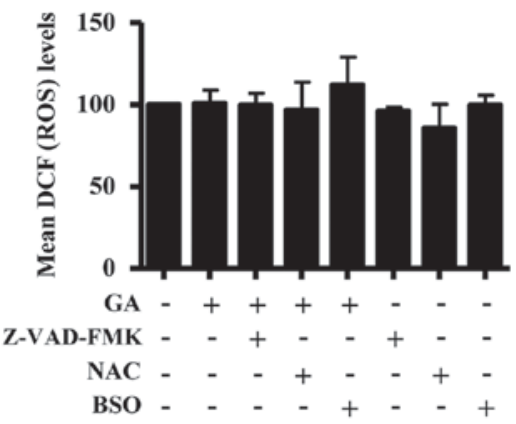

C
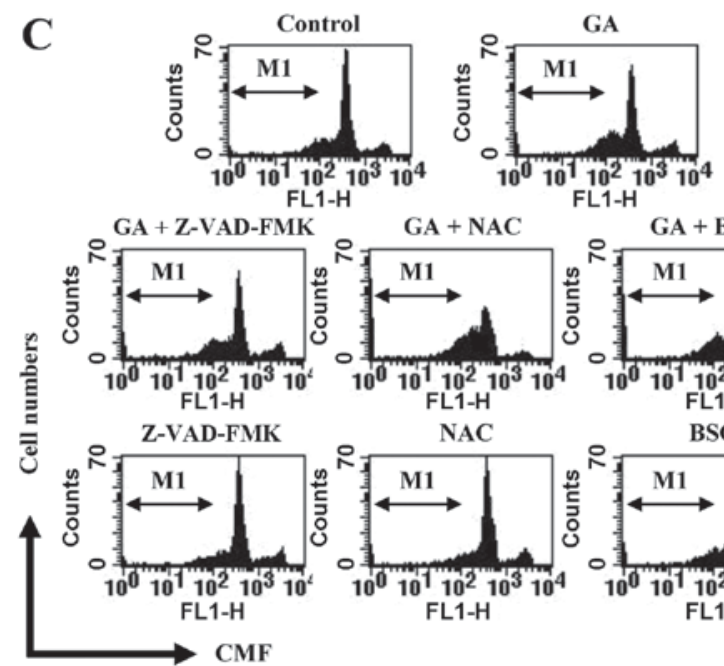

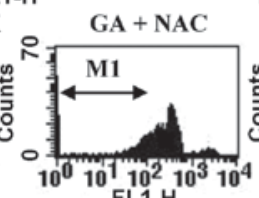

FL1-H $\mathbf{G A}+\mathbf{B S O}$

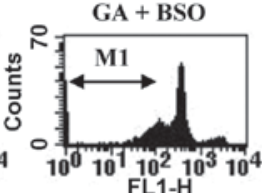

NAC

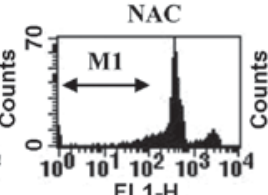

0
$10^{0} 10^{1}-10^{2}$
$\mathrm{FL}^{3}$

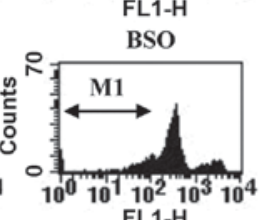

B

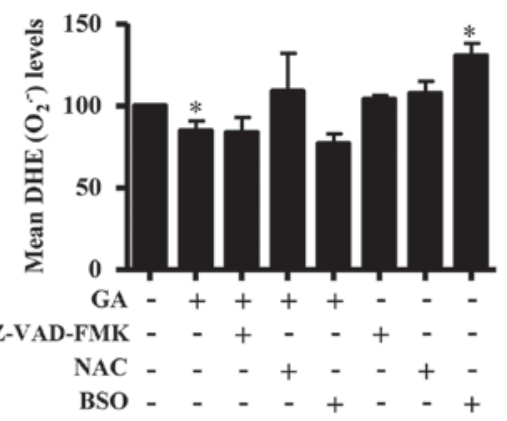

Figure 5. Effects of Z-VAD-FMK, NAC or BSO on ROS and GSH levels in GA-treated CPAECs. Exponentially growing cells were pretreated with Z-VAD-FMK $(15 \mu \mathrm{M})$, NAC $(2 \mathrm{mM})$ or BSO $(10 \mu \mathrm{M})$, followed by GA $(25 \mu \mathrm{M})$ for $24 \mathrm{~h}$; ROS and GSH levels were measured using a FACStar flow cytometer. (A) Mean ROS levels, as measured by DCF fluorescence intensity. (B) Mean $\mathrm{O}_{2}^{-}$levels, as measured by DHE fluorescence intensity. (C) Representative flow cytometry plots for (+) CMF staining in CPAECs. (D) Percentage of GSH-depleted cells, as measured by (-) CMF fluorescence from the M1 region in C. "P<0.05 compared with untreated $(0 \mu \mathrm{M} \mathrm{GA})$ control group; ${ }^{\mathrm{P}} \mathrm{P}<0.05$ compared with GA-treated control group. BSO, L-buthionine sulfoximine; CMF, 5-chloromethylfluorescein; CPAEC, calf pulmonary arterial endothelial cell; DCF, 2',7'-dichlorofluorescein; DHE, dihydroethidium; GA, gallic acid; GSH, glutathione; NAC, N-acetyl cysteine; $\mathrm{O}_{2}{ }^{--}$, superoxide anion; ROS, reactive oxygen species; Z-VAD-FMK, benzyloxycarbonyl-Val-Ala-Asp-fluoromethylketone. 
5 to $25 \mu \mathrm{M}$ GA treatment significantly decreased $\mathrm{O}_{2}{ }^{--}$levels in CPAECs, whereas exposure to $50 \mu \mathrm{M}$ GA had no effect. Therefore, in the present study, GA treatment appeared to exhibit more antioxidative than pro-oxidative properties in CPAECs. Notably, although NAC exposure did not affect ROS levels in GA-treated CPAECs, NAC co-treatment did result in reduced cell proliferation and increased cell death and $\Delta \Psi_{\mathrm{m}}$ loss in these cells; NAC treatment also strongly induced necrotic cell death in CPAECs treated with GA. A previous study reported a similar NAC-induced increase in growth inhibition and apoptotic death in GA-treated lung cancer cells (5). In the present study, neither Z-VAD-FMK nor BSO treatment significantly influenced ROS levels or cell death in GA-treated CPAECs. Cells treated with BSO alone exhibited increased $\mathrm{O}_{2}^{--}$levels without triggering cell death. Overall, the results from the present study suggest that GA-mediated CPAEC death is not related to oxidative stress. The precise roles of ROS in GA-induced CPAEC death require further investigation.

In general, apoptotic effects have been reported to be inversely proportional to GSH content in cells $(22,31,32)$. The intracellular GSH content may have a decisive effect on GA-induced cell death $(4,5,33)$. Similarly, results from the present study demonstrated that GA treatment dose-dependently decreased the number of GSH-positive cells in CPAECs. Z-VAD-FMK co-treatment did not affect the GA-induced depletion of GSH in CPAECs. In addition, NAC treatment, which showed increases in both necrotic and apoptotic cell deaths by GA, significantly augmented GSH depletion in these cells. Although it is recognized that NAC contains a thiol group and is a GSH precursor, this agent did not seem to be a GSH precursor in GA-treated CPAECs. However, NAC significantly attenuated both GSH depletion and cell death in propyl gallate- and MG132-treated CPAECs $(21,34)$. Thus, NAC may or may not be a GSH precursor depending on other agents used in co-treatments. In addition, when treated with BSO alone, there was a significant increase in the number of GSH-depleted cells; however, co-treatment with GA did not augment GSH depletion CPAECs. By contrast, previous studies have reported that BSO co-treatment enhanced GSH depletion and cell death in GA-treated lung cancer cells, fibroblasts and normal ECs $(5,28,33)$, and decreased GSH levels in MG132-treated CPAECs (35). Therefore, these data suggested that GSH content may serve a vital role in GA-induced cell death, and that BSO exposure may influence GSH levels dependent on cell type and co-incubation drugs.

In conclusion, GA exposure induced growth inhibition and death in CPAECs, which were revealed to be cause by GSH depletion rather than changes in ROS levels. The present data may provide useful information to understand the antiproliferative effects of GA in ECs, particularly CPAECs, in relation to the cellular changes in ROS and GSH levels.

\section{Acknowledgements}

The present study was supported by a grant from the National Research Foundation of Korea funded by the Korean government (Ministry of Science ICT and Future Planning; grant no. 2016R1A2B4007773).

\section{References}

1. Shahrzad S, Aoyagi K, Winter A, Koyama A and Bitsch I: Pharmacokinetics of gallic acid and its relative bioavailability from tea in healthy humans. J Nutr 131: 1207-1210, 2001.

2. Kang MS, Oh JS, Kang IC, Hong SJ and Choi CH: Inhibitory effect of methyl gallate and gallic acid on oral bacteria. J Microbiol 46: 744-750, 2008.

3. Kratz JM, Andrighetti-Fröhner CR, Leal PC, Leal PC, Nunes RJ, Yunes RA, Trybala E, Bergström T, Barardi CR and Simões CM: Evaluation of anti-HSV-2 activity of gallic acid and pentyl gallate. Biol Pharm Bull 31: 903-907, 2008.

4. You BR, Kim SZ, Kim SH and Park WH: Gallic acid-induced lung cancer cell death is accompanied by ROS increase and glutathione depletion. Mol Cell Biochem 357: 295-303, 2011.

5. You BR and Park WH: Gallic acid-induced lung cancer cell death is related to glutathione depletion as well as reactive oxygen species increase. Toxicol In Vitro 24: 1356-1362, 2010.

6. Inoue M, Sakaguchi N, Isuzugawa K, Tani H and Ogihara Y: Role of reactive oxygen species in gallic acid-induced apoptosis. Biol Pharm Bull 23: 1153-1157, 2000.

7. Agarwal C, Tyagi A and Agarwal R: Gallic acid causes inactivating phosphorylation of cde25A/cdc25C-cdc2 via ATM-Chk2 activation, leading to cell cycle arrest, and induces apoptosis in human prostate carcinoma DU145 cells. Mol Cancer Ther 5: 3294-3302, 2006.

8. Faried A, Kurnia D, Faried LS, Usman N, Miyazaki T, Kato H and Kuwano H: Anticancer effects of gallic acid isolated from Indonesian herbal medicine, Phaleria macrocarpa (Scheff.) Boerl, on human cancer cell lines. Int J Oncol 30: 605-613, 2007.

9. You BR, Moon HJ, Han YH and Park WH: Gallic acid inhibits the growth of HeLa cervical cancer cells via apoptosis and/or necrosis. Food Chem Toxicol 48: 1334-1340, 2010.

10. Chen HM, Wu YC, Chia YC, Chang FR, Hsu HK, Hsieh YC, Chen CC and Yuan SS: Gallic acid, a major component of Toona sinensis leaf extracts, contains a ROS-mediated anti-cancer activity in human prostate cancer cells. Cancer Lett 286: 161-171, 2009.

11. Apak R, Özyürek M, Güçlü K and Çapanoğlu E: Antioxidant activity/capacity measurement. 3. Reactive oxygen and nitrogen species (ROS/RNS) scavenging assays, oxidative stress biomarkers, and chromatographic/chemometric assays. J Agric Food Chem 64: 1046-1070, 2016.

12. Hsieh SC, Wu CH, Wu CC, Yen JH, Liu MC, Hsueh CM and Hsu SL: Gallic acid selectively induces the necrosis of activated hepatic stellate cells via a calcium-dependent calpain I activation pathway. Life Sci 102: 55-64, 2014.

13. Inoue M, Suzuki R, Sakaguchi N, Li Z, Takeda T, Ogihara Y, Jiang BY and Chen Y: Selective induction of cell death in cancer cells by gallic acid. Biol Pharm Bull 18: 1526-1530, 1995.

14. Sohi KK, Mittal N, Hundal MK and Khanduja KL: Gallic acid, an antioxidant, exhibits antiapoptotic potential in normal human lymphocytes: A Bcl-2 independent mechanism. J Nutr Sci Vitaminol (Tokyo) 49: 221-227, 2003.

15. Sameermahmood Z, Raji L, Saravanan T, Vaidya A, Mohan V and Balasubramanyam M: Gallic acid protects RINm5F beta-cells from glucolipotoxicity by its antiapoptotic and insulin-secretagogue actions. Phytother Res 24 (Suppl 1): S83-S94, 2010.

16. Strlic M, Radovic T, Kolar J and Pihlar B: Anti- and prooxidative properties of gallic acid in fenton-type systems. J Agric Food Chem 50: 6313-6317, 2002.

17. Sakagami $\mathrm{H}$ and Satoh K: Prooxidant action of two antioxidants: Ascorbic acid and gallic acid. Anticancer Res 17: 221-224, 1997.

18. Bassenge E: Endothelial function in different organs. Prog Cardiovasc Dis 39: 209-228, 1996.

19. Irani K: Oxidant signaling in vascular cell growth, death, and survival: A review of the roles of reactive oxygen species in smooth muscle and endothelial cell mitogenic and apoptotic signaling. Circ Res 87: 179-183, 2000.

20. Han YH and Park WH: Pyrogallol-induced calf pulmonary arterial endothelial cell death via caspase-dependent apoptosis and GSH depletion. Food Chem Toxicol 48: 558-563, 2010.

21. Han YH, Moon HJ, You BR and Park WH: Propyl gallate inhibits the growth of calf pulmonary arterial endothelial cells via glutathione depletion. Toxicol In Vitro 24: 1183-1189, 2010.

22. Park WH: Pyrogallol induces the death of human pulmonary fibroblast cells through ROS increase and GSH depletion. Int J Oncol 49: 785-792, 2016. 
23. You BR, Kim SH and Park WH: Reactive oxygen species, glutathione, and thioredoxin influence suberoyl bishydroxamic acid-induced apoptosis in A549 lung cancer cells. Tumour Biol 36: 3429-3439, 2015.

24. Park WH: Anti-apoptotic effect of caspase inhibitors on $\mathrm{H} 2 \mathrm{O} 2$-treated HeLa cells through early suppression of its oxidative stress. Oncol Rep 31: 2413-2421, 2014.

25. Han YH, Kim SZ, Kim SH and Park WH: Apoptosis in pyrogallol-treated Calu- 6 cells is correlated with the changes of intracellular GSH levels rather than ROS levels. Lung Cancer 59: 301-314, 2008.

26. You BR, Shin HR, Han BR and Park WH: PX-12 induces apoptosis in Calu- 6 cells in an oxidative stress-dependent manner. Tumour Biol 36: 2087-2095, 2015.

27. Han YH, Kim SH, Kim SZ and Park WH: Caspase inhibitor decreases apoptosis in pyrogallol-treated lung cancer Calu-6 cells via the prevention of GSH depletion. Int J Oncol 33: 1099-1105, 2008.

28. Park WH and Kim SH: Involvement of reactive oxygen species and glutathione in gallic acid-induced human umbilical vein endothelial cell death. Oncol Rep 28: 695-700, 2012.
29. You BR and Park WH: Gallic acid-induced human pulmonary fibroblast cell death is accompanied by increases in ROS level and GSH depletion. Drug Chem Toxicol 34: 38-44, 2011.

30. Ohno Y, Fukuda K, Takemura G, Toyota M, Watanabe M, Yasuda N, Xinbin Q, Maruyama R, Akao S, Gotou K, et al: Induction of apoptosis by gallic acid in lung cancer cells. Anticancer Drugs 10: 845-851, 1999.

31. Estrela JM, Ortega A and Obrador E: Glutathione in cancer biology and therapy. Crit Rev Clin Lab Sci 43: 143-181, 2006.

32. Han YH, Kim SZ, Kim SH and Park WH: Intracellular GSH level is a factor in As4.1 juxtaglomerular cell death by arsenic trioxide. J Cell Biochem 104: 995-1009, 2008.

33. You BR and Park WH: Enhancement of gallic acid-induced human pulmonary fibroblast cell death by $\mathrm{N}$-acetyl cysteine and L-buthionine sulfoximine. Hum Exp Toxicol 30: 992-999, 2011.

34. You BR and Park WH: MG132, a proteasome inhibitor-induced calf pulmonary arterial endothelial cell growth and death, are changed by MAPK inhibitors. Drug Chem Toxicol 34: 45-52, 2011.

35. Han YH, Kim SZ, Kim SH and Park WH: Reactive oxygen species and glutathione level changes by a proteasome inhibitor, MG132, partially affect calf pulmonary arterial endothelial cell death. Drug Chem Toxicol 33: 403-409, 2010. 